\title{
Bioelectrical impedance analysis to assess changes in total body water in patients with cancer.
}

Citation for published version (APA):

Simons, J. P., Schols, A. M. W. J., Westerterp, K. R., ten Velde, G. P. M., \& Wouters, E. F. M. (1999).

Bioelectrical impedance analysis to assess changes in total body water in patients with cancer. Clinical Nutrition, 18(1), 35-39. https://doi.org/10.1016/S0261-5614(99)80047-8

Document status and date:

Published: 01/01/1999

DOI:

10.1016/S0261-5614(99)80047-8

Document Version:

Publisher's PDF, also known as Version of record

Document license:

Taverne

Please check the document version of this publication:

- A submitted manuscript is the version of the article upon submission and before peer-review. There can be important differences between the submitted version and the official published version of record.

People interested in the research are advised to contact the author for the final version of the publication, or visit the DOI to the publisher's website.

- The final author version and the galley proof are versions of the publication after peer review.

- The final published version features the final layout of the paper including the volume, issue and page numbers.

Link to publication

\footnotetext{
General rights rights.

- You may freely distribute the URL identifying the publication in the public portal. please follow below link for the End User Agreement:

www.umlib.nl/taverne-license

Take down policy

If you believe that this document breaches copyright please contact us at:

repository@maastrichtuniversity.nl

providing details and we will investigate your claim.
}

Copyright and moral rights for the publications made accessible in the public portal are retained by the authors and/or other copyright owners and it is a condition of accessing publications that users recognise and abide by the legal requirements associated with these

- Users may download and print one copy of any publication from the public portal for the purpose of private study or research.

- You may not further distribute the material or use it for any profit-making activity or commercial gain

If the publication is distributed under the terms of Article $25 \mathrm{fa}$ of the Dutch Copyright Act, indicated by the "Taverne" license above, 


\title{
Bioelectrical impedance analysis to assess changes in total body water in patients with cancer
}

\author{
J. P. F. H. A. SIMONS, A. M. W. J. SCHOLS, K. R. WESTERTERP*, G. P. M. TEN VELDE, E. F. M. WOUTERS
}

Departments of Pulmonology and *Human Biology, Maastricht University, PO Box 616, 6200 MD Maastricht, The Netherlands (Correspondence to: JPFHAS, Department of Pulmonology, Astmacentrum Hornerheide, Hornerheide 1, 6085 NM Horn, The Netherlands)

\begin{abstract}
Predominantly based on studies in obese individuals, the applicability of single-frequency bioelectrical impedance analysis (BIA) to measure changes in total body water and fat-free mass has been questioned. To further clarify this issue, we compared changes in BIA-derived height ${ }^{2} / \mathrm{resistance}\left(\mathrm{ht}^{2} / \mathrm{R}\right)$ with changes in total body water (deuterium dilution, $\Delta$-TBWdeu) in cancer patients participating in a clinical trial. Thirty-three patients (mean body mass index $23.2 \pm 3.5 \mathrm{~kg} / \mathrm{m}^{2}$ ) were studied after an average follow-up of 11 weeks. Changes in TBWdeu occurred in both directions (mean $+0.2 \pm 1.6 \mathrm{~L}$, range -3.3 to $+3.1 \mathrm{~L})$. These changes were significantly predicted by changes in $\mathrm{ht}^{2} / \mathrm{R}\left(r^{2} 0.43, P<0.0001, \mathrm{SEE} 1.22 \mathrm{~L}\right)$, although precision was poor (residual SD $1.2 \mathrm{~L}$ ). There were in this regard no significant differences between patients with and without underweight. We conclude that in underweight and normal-weight cancer patients, BIA-derived changes in $\mathrm{ht}^{2} / \mathrm{R}$ significantly predict changes in total body water assessed by deuterium dilution.
\end{abstract}

Key words: body composition; BIA; cancer

\section{Introduction}

Bioelectrical impedance analysis (BIA) is a body composition analysis technique to measure fat mass and fat-free mass (FFM) according to a two-compartment model. Single-frequency BIA is based on the principle that a fixed, low-voltage, high-frequency current, introduced into the human body, is conducted almost completely through the fluid compartment of the FFM, which is an equivalent of total body water (TBW) $(1,2)$. The opposition to the flow of this current, the resistance $(R)$, is measured. The assumption that $\mathrm{R}$ can be used to predict TBW and FFM has been proven by many studies in healthy individuals. Particularly

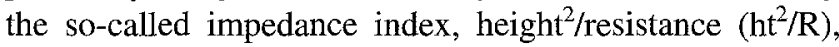
proved to be a significant predictor (3-14).

Although already widely used in prospective clinical trials (15-19), the applicability of BIA to measure changes in TBW and FFM is far from clear. Several studies, most of which were performed in obese individuals on a weight loss program, showed that the reliability of BIA to measure changes in TBW or FFM was disappointing (20-24). To expand our knowledge on the ability of BIA to predict changes in TBW, we measured changes in BIA-derived $\mathrm{ht}^{2} / \mathrm{R}$ in advanced-stage cancer patients who participated in a randomized placebo-controlled trial investigating the effects of a synthetic progestagen on food intake and body composition (25). In this study, TBW was assessed by deuterium dilution, which was thus used as a reference method for the validation of BIA.

\section{Materials and methods}

Patients

Patients with the following histologically or cytologically diagnosed, incurable malignancies were considered eligible: non-small-cell carcinoma of the lung; mesothelioma; carcinoma of the digestive tract or pancreas; carcinoma of the kidney, bladder or ureter; and disseminated carcinoma of unknown origin. All patients were required to have a Karnofsky performance status score of at least $60 \%$. The protocol was in accordance with the Helsinki Declaration of 1975, as revised in 1983, and was approved by the institutional review board for human research of the University Hospital Maastricht. Written informed consent was obtained from all patients.

\section{Study design}

The study duration was 12 weeks. At baseline and after 6 and 12 weeks, body weight, BIA-derived R and deuterium dilution-derived TBW (TBWdeu) were assessed.

\section{Height and weight}

Height (ht) was measured, without shoes, to the nearest $0.1 \mathrm{~cm}$ by using a wall-mounted stadiometer. Body weight (wt) was measured in the morning, in the fasted state, after voiding and without clothing and shoes, to the nearest $0.1 \mathrm{~kg}$ by using a beam scale (SECA, Hamburg, Germany).

\section{Bioelectrical impedance analysis}

$\mathrm{R}$ was also measured in the morning, in the fasted state and 
after voiding, by using a $800 \mu \mathrm{A}, 50-\mathrm{kHz}$ tetrapolar impedance plethysmograph (BIA 101, RJL systems Inc, Detroit, MI). The measurements were performed in the supine position on the right side of the body. As described by Lukaski et al. (9), two disposable pregelled electrodes were affixed to the dorsum of the right hand and two to the dorsum of the right foot.

\section{Total body water}

The evening before each visit to the hospital, at approximately 2300 , all patients drank a weighted dose of approximately $4.00 \mathrm{~g}$ deuterium ( 99.84 atom percent excess) in $50 \mathrm{~mL}$ water. Then the bottle was rinsed once with approximately $50 \mathrm{~mL}$ tap water, which was also drunk. Thereafter, the patients had to refrain from eating and drinking. They were asked to void at least once at home before attending the hospital. Before and $10 \mathrm{~h}$ after drinking the deuterium water, a urine sample was taken. Deuterium was measured in duplicate in these two samples by using an isotope ratiomass spectrometer (Aqua Sira, VG Isogas, Cheshire, UK) (26). Comparison of the duplicate measurements showed a precision $>99 \%$. TBWdeu was calculated by dividing the measured volume of distribution of deuterium by 1.04 , thereby correcting for the exchange of deuterium with non-aqueous hydrogen (27). The use of this test protocol with an overnight equilibration period of 10 hours has been extensively validated in our laboratory (28). It was shown that TBW assessed by using this protocol corresponds very well (bias 1\%) with TBW derived from hydrodensitometry (28).

\section{Statistical analysis}

Results are expressed as mean \pm SD. For all statistics, significance was determined at the 5\% level (two-sided). The prediction of $\Delta$-TBWdeu by $\Delta$-wt and $\Delta-\mathrm{ht}^{2} / \mathrm{R}$ was evaluated by linear-regression analysis. In addition, the agreement between methods was evaluated by plotting the residuals of the regression of $\Delta$-TBWdeu on $\Delta-\mathrm{ht}^{2} / \mathrm{R}$ relative to $\Delta$-TBWdeu. For all analyses, the statistical package SPSS/PC+ (version 6.0-Windows; SPSS Inc., Chicago, USA) was used. Slopes and intercepts of different regression lines were statistically compared by using a small-sample $t$ test as described by Kleinbaum et al. (29). Subjects were considered non-evaluable in case of the development of peripheral edema, as it could not be excluded that such large fluid shifts would substantially bias the reliability of the BIA-prediction of TBW change.

\section{Results}

Fifty-four advanced-stage cancer patients participated in the clinical trial that formed the base for the present study (25). In 38 patients, at least one follow-up measurement of both BIA and deuterium dilution was available. The other patients dropped-out before reaching the first evaluation (at
Table 1 Baseline characteristics ${ }^{1}$

\begin{tabular}{lc}
\hline & $(n=28$ males, 5 females $)$ \\
\hline Age $(\mathrm{y})$ & $66 \pm 8$ \\
Height $(\mathrm{cm})$ & $169 \pm 7$ \\
Weight $(\mathrm{kg})$ & $66.3 \pm 10.0$ \\
PIBW $(\%)^{2}$ & $101 \pm 15$ \\
Body mass index $\left(\mathrm{kg} / \mathrm{m}^{2}\right)$ & $23.2 \pm 3.5$ \\
Weight loss $(\%)^{3}$ & $8.4 \pm 9.0$ \\
Resistance $(\Omega)$ & $535 \pm 85$ \\
TBWdeu $(\mathrm{L})^{4}$ & $37.2 \pm 5.3$ \\
FFMdeu/wt $(\%)^{5}$ & \\
$\quad$ males & $79.3 \pm 6.1$ \\
$\quad$ females & $66.1 \pm 7.9$ \\
Blood urea nitrogen $(\mathrm{mmol} / \mathrm{L})$ & $6.1 \pm 1.8$ \\
Creatinine $(\mu \mathrm{mol} / \mathrm{L})$ & $83 \pm 18$ \\
\hline
\end{tabular}

${ }^{\mathrm{l}}$ Mean \pm SD. ${ }^{2}$ Weight expressed as percentage of ideal body weight. ${ }^{3}$ Weight loss as percentage of pre-illness weight. ${ }^{4}$ Total body water by deuterium dilution. ${ }^{5}$ Fat-free mass by deuterium dilution (TBWdeu /0.73) as percentage of body weight.

6 weeks) due to death or physical deterioration $(n=6)$, side effects $(n=4)$, refusal to continue $(n=2)$, protocol violation $(n=2)$, mechanical obstruction of the digestive tract $(n=1)$ and hospitalization due to sigmoid perforation and peritonitis $(n=1)$. As five of the patients with available followup measurements developed peripheral edema, the total number of patients used in the analysis was 33 . Of these patients, the baseline measurements and those made on the last follow-up visit (week 6 in seven patients), were analyzed. In Table 1, the baseline characteristics of these patients are given.

During the study, changes in body weight as well as TBWdeu occurred in both directions: mean weight change was $+0.1 \pm 3.7 \mathrm{~kg}$, range -7.6 to $+13.7 \mathrm{~kg}$; mean TBWdeu change amounted to $+0.2 \pm 1.6 \mathrm{~L}$, range -3.3 to $+3.1 \mathrm{~L}$.

$\Delta-\mathrm{Wt}$ and $\Delta-\mathrm{ht}^{2} / \mathrm{R}$ were significantly correlated with $\Delta$ TBWdeu (respective $r 0.43[P=0.01]$ and $0.66[P<0.0001]$ ). On stepwise regression analysis, however, only $\Delta-\mathrm{ht}^{2} / \mathrm{R}$ was identified as significant independent predictor of $\Delta$-TBWdeu $\left(\mathrm{y}=0.09+0.3708 \mathrm{x}\right.$, SEE $1.22 \mathrm{~L}, r^{2}=0.43$, $P<0.0001$ ). In Figure 1, the regression line of $\Delta$-TBWdeu on $\Delta-\mathrm{ht}^{2} / \mathrm{R}$ is shown. To further document the predictive

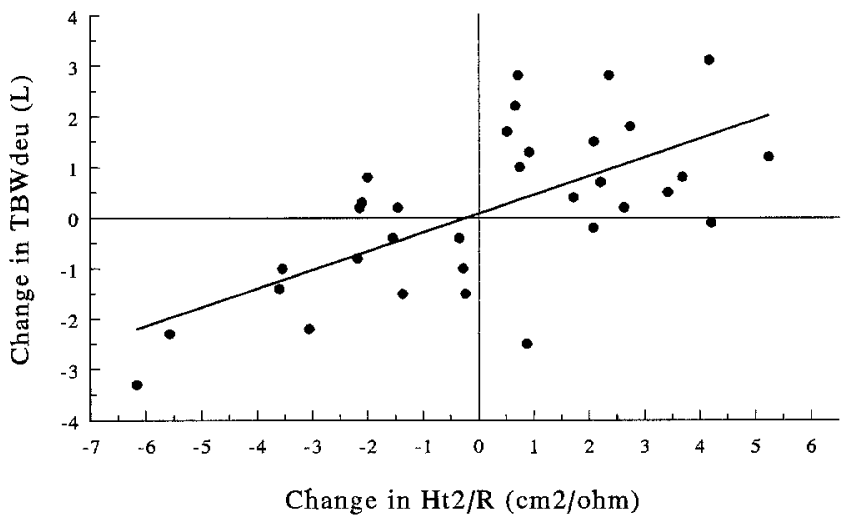

Fig. 1 Linear regression of changes in total body water by deuterium dilution (TBWdeu) on changes in height ${ }^{2} /$ resistance $\left(\mathrm{ht}^{2} / \mathrm{R}\right)$ by bioelectrical impedance analysis. Characteristics of the regression line: $y=0.09+0.3708 x$, SEE 1.22 L, $r^{2}=0.43, P<0.0001$. 


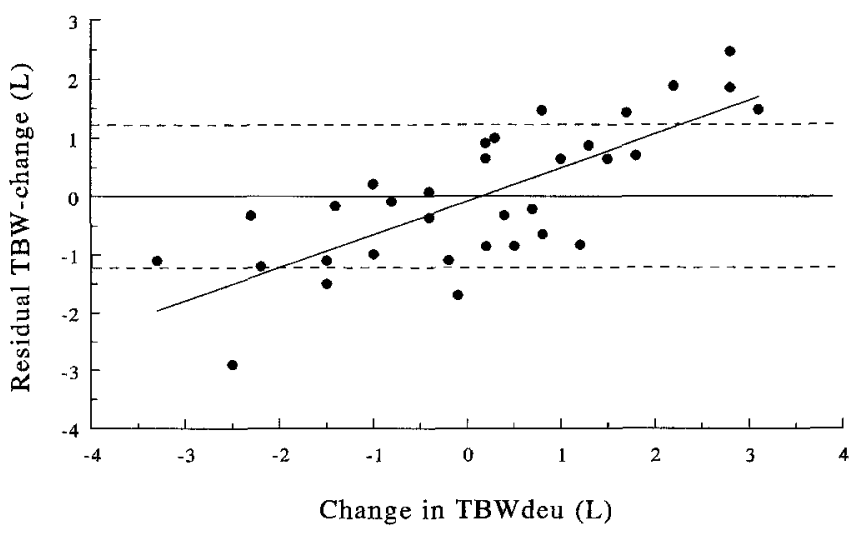

Fig. 2 Plot of the residuals of the regression of $\Delta$-TBWdeu on $\Delta-h^{2} / R$ in relation to the corresponding changes in TBWdeu. The residual SD is represented by the dashed lines. Correlation characteristics: $r=0.75$, $P<0.0001$.

power of BIA to assess TBW-changes, the residuals of the regression of $\Delta$-TBWdeu on $\Delta-\mathrm{ht}^{2} / \mathrm{R}$ are shown in Figure 2. The residuals are presented in relation to the corresponding changes in TBWdeu. The residual SD amounted to $1.2 \mathrm{~L}$. The residual values and observed changes in TBWdeu proved to be positively correlated $(r=0.75, P<0.0001)$, indicating that an increasing magnitude of TBW-change was associated with an increasing underestimation of TBW-change by BIA.

To investigate whether there was a difference in the prediction of $\Delta$-TBWdeu by $\Delta-\mathrm{ht}^{2} / \mathrm{R}$ in underweight patients (arbitrarily defined as having a body weight below 95\% of the ideal body weight [PIBW] [30]) and normal-weight patients, a separate linear-regression-analysis of $\Delta$-TBWdeu on $\Delta-\mathrm{ht}^{2} / \mathrm{R}$ was performed in each subgroup. Mean PIBW was $85 \pm 7 \%$ in the underweight patients $(n=11)$ and $110 \pm$ $11 \%$ in the normal-weight subjects $(n=22)$. The characteristics of the regression line of the underweight patients $\left(\mathrm{y}=0.09+0.3483 \mathrm{x}, \mathrm{SEE} 1.16 \mathrm{~L}, r^{2}=0.42, P=0.03\right)$ were not significantly different from those of the regression line of the normal-weight patients $(y=0.09+0.3802 x$, SEE $\left.1.30 \mathrm{~L}, r^{2}=0.43, P<0.001\right)$; the $95 \%$ confidence interval for the difference between slopes was -0.378 to 0.314 .

\section{Discussion}

The results of the present study indicate that in cancer patients, with or without underweight, the BIA-parameter $\Delta-\mathrm{ht}^{2} / \mathrm{R}$ is a significant predictor of $\Delta-\mathrm{TBW}$, and that the use of $\Delta$-wt as an additional factor does not further improve the prediction.

These results are in contrast with those of several other investigators, who overtly raised doubts about the ability and reliability of BIA to detect changes in TBW and FFM in longitudinal studies. Some even suggested that $\Delta$-wt is a better predictor of $\Delta$-TBW than $\Delta-\mathrm{R}(20,31)$. In 1989 , Deurenberg et al. (21) reported a study in 13 obese women losing weight on a 8 -week diet. In this study, mean $\Delta$-FFM measured by densitometry was significantly under-estimated by BIA (respective mean $\Delta$-FFM: $-2.3 \mathrm{~kg}$ and $-0.6 \mathrm{~kg}$ ). No correlation data were reported. In 1992, Forbes et al. (20) reported in a review of six studies in adults who incurred a change in body weight and FFM as a result of diet or diet plus exercise, that in four studies no significant correlation was found between $\Delta-\mathrm{R}$ and $\Delta$-FFM. Also in 1992, van der Kooy et al. (22) reported the results of a study in 84 obese patients losing weight on a 13-week diet. In this study, no correlation was found between $\Delta-\mathrm{R}$ and $\Delta$-FFM measured by densitometry. BIA-derived $\Delta$-FFM was calculated by using three different previously published prediction equations. In contrast with the Deurenberg study, all equations, in a varying degree, significantly over-estimated mean $\Delta$-FFM. In 1995, a study was reported by Beshyah et al. (23) investigating the changes in FFM assessed by three methods (BIA, dual-energy X-ray absorptiometry [DXA] and total body potassium $[\mathrm{TBK}]$ ) in a group of 14 hypopituitary adults during growth hormone treatment. No significant correlation was found between $\triangle$-FFMbia and $\Delta$-FFM assessed by DXA and TBK. BIA strongly overestimated $\triangle$-FFM measured by TBK, but accurately predicted mean $\Delta$-FFM measured by DXA. In contrast with the previous studies, Valtueña et al. (32) reported in 1995 in nine obese women, losing weight on a 4-week lowenergy diet, a significant correlation between densitometric $\Delta$-FFM and $\Delta$-FFMbia ( $r=0.69, P<0.05$, SEE not stated). Accuracy was relatively good: mean densitometric $\Delta$-FFM amounted to $-3.4 \mathrm{~kg}$, versus $-2.9 \mathrm{~kg}$ for $\Delta$-FFMbia. In a recent study by Abrahamsen et al. in 18 hemodialysis patients before and after ultrafiltration (24), no significant correlation was observed between $\Delta-\mathrm{R}$ measured by BIA and $\triangle$-TBW measured as weight reduction by dialysis.

Why did the present study show a significant correlation between $\Delta-\mathrm{ht}^{2} / \mathrm{R}$ and $\Delta$-TBW, while most of the longitudinal BIA studies, reviewed above, did not? Apart from differences in group size, rapidity, magnitude and range of TBW changes, and reference methods used, an additional explanation could be the fact that in most studies the validity of BIA to measure changes in FFM was investigated in obese individuals on a weight-loss program. Several previous studies revealed that obesity, on a body compositional level, is characterized by an absolute elevation of ICW and an absolute and relative increase of ECW, resulting in an increased hydration coefficient of the FFM and an increased ECW/ICW ratio $(33,34)$. It was also shown that weight loss in these patients is accompanied by a decrease in ICW, while ECW remains stable or decreases only slightly $(33,35)$. If the $50-\mathrm{kHz} \mathrm{BLA}$-current is more easily conducted through the ECW than through the ICW, which is suggested in literature (36), over-time changes in $\mathrm{ECW} / \mathrm{ICW}$ ratio, and inter-individual variation in these changes, might importantly contribute to the poor BIA reliability observed in most follow-up obesity studies. In addition, the results might have been further confounded by concomitant changes in the hydration coefficient of the FFM, for example due to ICW losses mainly consisting of (glycogen-bound) pure water.

Finally, in some of the reviewed studies the reliability of BIA might have been also influenced by the use of TBW 
prediction equations that, in addition to $\mathrm{R}$, contain variables (for example weight) of which changes are not necessarily proportionally related to changes in TBW.

Although in the present study it was shown that changes in BIA-derived $\mathrm{ht}^{2} / \mathrm{R}$ significantly predict changes in TBW in normal-weight and underweight individuals, some drawbacks of the technique need further discussion. Firstly, the precision of the prediction of TBW-changes is poor. This statement is based on the finding of a high residual SD of the prediction $(1.2 \mathrm{~L})$ in relation to the SD and range of the changes in TBWdeu observed (respectively $1.6 \mathrm{~L}$ and -3.3 to $+3.1 \mathrm{~L}$ ). This poor precision was shown to be due (at least in part) to the fact that BIA progressively underestimates TBW-changes as these changes become larger. Secondly, it should be stressed that the use of different prediction equations (as presently available in literature) to calculate TBW from $\mathrm{R}$ not only leads to different absolute values of TBW $(37,38)$, but also to different values of TBWchange. The larger the relative importance of $\mathrm{R}$ (or $\mathrm{ht}^{2} / \mathrm{R}$ ) in the formula is, the larger the assessed $\Delta$-TBW for a given $\Delta-\mathrm{R}$ will be. When for example $\mathrm{R}$ changes from $540 \mathrm{ohm}$ to $500 \mathrm{ohm}$ and weight from $66 \mathrm{~kg}$ to $71 \mathrm{~kg}$ in a 65 yearold-male with a height of $170 \mathrm{~cm}$, TBWbia will change from $33.2 \mathrm{~L}$ to $35.3 \mathrm{~L}$ when the formula developed by Deurenberg et al. (TBW $=0.72 *\left(0.340\left(\mathrm{ht}^{2} / \mathrm{R}\right)+0.1534(\mathrm{ht})\right.$ $+0.273(\mathrm{wt})-0.127(\mathrm{~A})+4.56(\mathrm{sex} ; \mathrm{m}=1, \mathrm{f}=0)-12.44)$ [5]) is used, versus $35.9 \mathrm{~L}$ to $38.8 \mathrm{~L}$ in case of the formula by Kushner et al. $\left(\mathrm{TBW}=0.59\left(\mathrm{ht}^{2} / \mathrm{R}\right)+0.065(\mathrm{wt})+0.04\right.$ [13]). The latter increase in TBWbia is $\approx 40 \%$ higher than the increase assessed by using the first formula. This inherent problem of quantification can only be circumvented by exclusively analyzing and reporting within- and between-group changes in $\mathrm{R}$ or $\mathrm{ht}^{2} / \mathrm{R}$. When quantification is nevertheless desired, which probably often will be the case, it is obviously important to report in addition to (the analysis of) the 'crude' $\mathrm{R}$ values, the exact formula by which TBW or FFM is calculated. Unfortunately, however, this is not at all common practice in prospective clinical studies to date.

\section{References}

1. Nyboer J. Workable vòlume and flow concepts of bio-segments by electrical impedance plethysmography. T-I-T J Life Sci 1972; 2: 1-13

2. Lukaski H C, Johnson P E, Bolonchuk W W, Lykken G I. Assessment of fat free mass using bioelectrical impedance measurements of the human body. Am J Clin Nutr 1985; 41: 810-817

3. Kushner R F. Bioelectrical impedance analysis: a review of principles and applications. J Am Coll Nutr 1992; 11: 199-209

4. Deurenberg P, van der Kooy K, Evers P, Hulshof T. Assessment of body composition by bioelectrical impedance in a population aged $>60$ y. Am J Clin Nutr 1990; 51: 3-6

5. Deurenberg P, van der Kooy K, Leenen R, Weststrate J A, Seidell J C. Sex and age specific prediction formulas for estimating body composition from bioelectrical impedance: a cross-validation study Int J Obes 1991; 15: 17-25

6. Graves J E, Pollock M L, Colvin A B, Van Loan M, Lohman T G Comparison of different bioelectrical impedance analysers in the prediction of body composition. Am J Hum Biol 1989; 1: 603-611

7. Heitmann B L. Prediction of body water and fat in adult Danes from measurement of electrical impedance. A validation study. Int J Obes 1990; 14: 789-802
8. Kushner R F, Schoeller D A. Estimation of total body water by bioelectrical impedance analysis. Am J Clin Nutr 1986; 44: 417-424

9. Lukaski H C, Bolonchuk W W, Hall C B, Siders W A. Validation of the tetrapolar bioelectrical impedance method to assess human body composition. J Appl Physiol 1986; 60: 1327-1332

10. Lukaski $\mathrm{H} \mathrm{C}$, Bolonchuk W W. Estimation of body fluid volumes using tetrapolar bioelectrical impedance measurements. Aviat Space Environ Med 1988; 59: 1163-1169

11. Segal K R, Van Loan M, Fitzgerald P I, Hodgdon J A, Van Itallie $T$ B. Lean body mass estimation by bioelectrical impedance analysis: a tour-site cross-validation study. Am J Clin Nutr 1988; 47: 7-14

12. Van Loan M, Mayclin P. Bioelectrical impedance analysis: is it a reliable estimator of lean body mass and total body water? Human Biol 1987; 59: 299-309

13. Kushner R F, Schoeller D A; Fjeld C R, Danford L. Is the impedance index $\left(\mathrm{ht}^{2} / \mathrm{R}\right)$ significant in predicting total body water? Am J Clin Nutr 1992; 56: 835-839

14. Zillikens $\mathbf{M ~ C}$, Conway $\mathbf{J} \mathbf{M}$. The estimation of total body water by bioelectrical impedance analysis in blacks. Am J Hum Biol 1991; 3: $25-32$

15. Wigmore S J, Plesters C E, Richardson R A, Fearon K C. Changes in nutritional status associated with unresectable pancreatic cancer. $\mathrm{Br} \mathrm{J}$ Cancer 1997; 75: 106-109

16. Oster $M H$, Enders $S \mathrm{R}$, Samuels $\mathrm{S} J$ et al. Megestrol acetate in patients with AIDS and cachexia. Ann Int Med 1994; 121:400-408

17. Von Roenn J H, Armstrong D, Kotler D P et al. Megestrol acetate in patients with AIDS-related cachexia. Ann Int Med 1994; 121: 393-399

18. Mulligan K, Grunfeld C, Hellerstein M K, Neese R A, Schambelan M. Anabolic effects of recombinant human growth hormone in patients with wasting associated with human immunodeficiency virus infection. J Clin Endocrinol Metab 1993; 77: 956-962

19. Hellerstein $\mathrm{M} \mathrm{K}, \mathrm{Wu} \mathrm{K}, \mathrm{McGrath} \mathrm{M}$ et al. Effects of dietary $\mathrm{n}-3$ fatty acid supplementation in men with weight loss associated with the acquired immunodeficiency syndrome: relation to indices of cytokine production. J Acquir Immune Defic Syndr Human Retrovir 1996; 11: $258-270$

20. Forbes G B, Simon W, Amatruda J M. Is bioimpedance a good predictor of body-composition change? Am J Clin Nutr 1992; 56: 4-6

21. Deurenberg P, Weststrate J A, Hautvast J G. Changes in fat-free mass during weight loss measured by bioelectrical impedance and by densitometry. Am J Clin Nutr 1989; 49: 33-36

22. van der Kooy K, Leenen R, Deurenberg P, Seidell J C, Westerterp $K$ R, Hautvast J G. Changes in fat-free mass in obese subjects after weight loss: a comparison of body composition measures. Int J Obes 1992; 16: 675-683

23. Beshyah S A, Freemantle C, Thomas E, Page B, Murphy M, Johnston D G. Comparison of measurements of body composition by total body potassium, bioimpedance analysis, and dual-energy $\mathrm{X}$-ray absorptiometry in hypopituitary adults before and during growth hormone treatment. Am J Clin Nutr 1995; 61: 1186-1194

24. Abrahamsen B, Hansen T B, Hogsberg I M, Pedersen F B, BeckNielsen $\mathrm{H}$. Impact of hemodialysis on dual X-ray absorptiometry, bioelectrical impedance measurements, and anthropometry. Am J Clin Nutr 1996; 63: 80-86

25. Simons J P, Schols A M, Hoefnagels J M, Westerterp K R, ten Velde G P, Wouters E F. The effects of medroxyprogesterone acetate on food intake, body composition and resting energy expenditure in advanced stage non-hormone-sensitive cancer: a randomized placebocontrolled study. Cancer 1998; 82: 553-560

26. Barrie A, Coward W A. A rapid analytical technique for the determination of energy expenditure by the doubly labelled water method. Biomed Mass Spectrom 1985; 12: 535-541

27. Schoeller D A, van Santen E, Peterson D W, Dietz W, Jaspan J, Klein $\mathrm{P}$ D. Total body water measurement in humans with ${ }^{18} \mathrm{O}$ and ${ }^{2} \mathrm{H}$ labeled water. Am J Clin Nutr 1980; 33: 2686-2693

28. Westerterp K R, Wouters L, van Marken Lichtenbelt W D. The Maastricht protocol for the measurement of body composition and energy expenditure with labeled water. Obes Res 1995; 3: 49-57 (suppl 1)

29. Kleinbaum D G, Kupper L L, Muller K E. Applied regression analysis and other multivariate methods. Boston: PWS-Kent Publishing Company, 1988

30. Metropolitan Life Insurance Company. New weight standards for men and women. Statist Bull Metrop Life Found 1983; 64: 1-4

31. Mazess R B. Do bioimpedance changes reflect weight, not composition? Am J Clin Nutr 1991; 53: 178-179 (letter) 
32. Valtueña S, Blanch S, Barenys M, Solà R, Salas-Salvadó J. Changes in body composition and resting energy expenditure after rapid weight loss: is there an energy-metabolism adaptation in obese patients? Int J Obes 1995; 19: 119-125

33. Mazariegos M, Kral J G, Wang J et al. Body composition and surgical treatment of obesity. Effects of weight loss on fluid distribution. Ann Surg 1992; 216: 69-73

34. Albu S, Lichtman S, Heymsfield S, Wang J, Pierson R N, PiSunyer F X. Reassessment of body composition models in morbidly obese. FASEB J 1989; 3: A336

35. Zimmermann M E, Andersson H, Lundell L, Olbe L. Alterations in body composition after gastroplasty for morbid obesity. Scand J
Gastroenterol 1990; 25: 263-268

36. Deurenberg P, van der Kooy K, Leenen R, Schouten F J M. Body impedance is largely dependent on the intra- and extracellular water distribution. Eur J Clin Nutr 1989; 43: 845-853

37. Fuller $\mathrm{N}$ J. Comparison of abilities of various interpretations of bio-electrical impedance to predict reference method body composition assessment. Clin Nutr 1993; 12: 236-242

38. Simons J P, Schols A M, Westerterp K R, ten Velde G P, Wouters E F. The use of bioelectrical impedance analysis to predict total body water in patients with cancer cachexia. Am J Clin Nutr 1995; 61: 741-745 